\title{
KRAS Mutation Analysis Testing Method
}

National Cancer Institute

\section{Source}

National Cancer Institute. KRAS Mutation Analysis Testing Method. NCI Thesaurus. Code C158905.

A request to enter the specific molecular analysis method used to detect and identify mutations in the KRAS gene. 